\title{
RANCANG BANGUN SISTEM INFORMASI ADMINISTRASI PKM UNIVERSITAS LAMPUNG BERBASIS WEB MENGGUNAKAN METODE RATIONAL UNIFIED PROCESS (RUP)
}

\author{
${ }^{1}$ Ayu Taqiya Ulfa, ${ }^{2}$ Astria Hijriani \& ${ }^{3}$ Rico Andrian \\ 1,2,3 Jurusan Ilmu Komputer FMIPA Unila
}

\begin{abstract}
Administrative information system of the Program Kreativitas Mahasiswa (PKM) of Lampung University is a web-based information system developed to assist administrative process in the implementation of PKM at university level, to record participants of PKM University of Lampung, to disseminate information about PKM, and to provide reference of PKM document of University of Lampung students. Information system administration PKM University of Lampung was developed using the programming language PHP and MySQL. The system development method used is the Rational Unified Process (RUP) method. The RUP divides one development cycle into four phases. The phases of the RUP are inception, construction, elaboration, and transition. Each phase in the workflow process that starts from business modeling, requirement, analysis and design, implementation, testing, and finally deployment. The process in the inception phase is business modeling and requirement, then at elaboration stage is analysis and design and implementation. The process at the construction phase is testing, then process at the transition phase is deployment. Software product testing is done by equivalence partitioning testing and alpha test version. Test results reached success rate $91.41 \%$, so it can be concluded that the functions on the system running well and the system can already to use.
\end{abstract}

Keywords: $M y S Q L, P K M ; P H P ; R U P$, web

\section{Pendahuluan}

Program Kreativitas Mahasiswa (PKM) merupakan salah satu upaya yang dilakukan oleh Direktorat Riset dan Pengabdian Masyarakat (semula Direktorat Penelitian dan Pengabdian kepada Masyarakat Ditjen Dikti), Direktorat Jenderal Penguatan Riset dan Pengembangan, Kementerian Ristek Dikti untuk meningkatkan mutu peserta didik (mahasiswa) di Perguruan Tinggi agar kelak dapat menjadi anggota masyarakat yang memiliki kemampuan akademis dan / atau professional yang dapat menerapkan, mengembangkan dan meyebarluaskan ilmu pengetahuan, teknologi dan/atau kesenian serta memperkaya budaya nasional [1].

Universitas Lampung memiliki bagian-bagian yang menangani pelayanan dan administrasi PKM yaitu Biro Akademik dan kemahasiswaan Universitas Lampung (BAK Unila). BAK Unila memberi pelayanan dan penyebarluasan informasi terkait akademik dan kemahasiswaan. Bentuk pelayanan BAK Unila salah satunya yaitu melayani administrasi Program Kreatifitas Mahasiswa (PKM). PKM saat ini menjadi ajang kompetisi bergengsi dan diminati oleh mahasiswa Universitas Lampung, hal tersebut dibuktikan dengan jumlah peserta PKM yang terus bertambah setiap tahunnya. Proposal PKM yang diajukan pada tahun 2013 tecatat 139 proposal, sedangkan pada tahun 2014 mencapai 484 proposal dan pada tahun 2015 mencapai 1696 proposal.

Peserta PKM terus meningkat setiap tahunnya dapat menyebabkan bermunculan permasalahanpermasalahan baru dalam proses pelayanan dan administrasi PKM. Permasalahan yang terjadi antara lain lamanya proses administrasi, penyebarluasan informasi yang kurang mendukung, serta rekap data berkas peserta PKM yang masih manual sehingga menyulitkan untuk menyaring jika terdapat judul yang sama. Proses administrasi pelayanan PKM di Universitas Lampung yang 
masih dilakukan secara manual belum terdapat sistem yang dapat membantu memonitoring perkembangan setiap prosesnya. Proses tesebut juga berdampak pada sulitnya memonitoring data peserta untuk konsumsi internal stakeholder Universitas Lampung.

Sistem informasi mampu menjadi alat bantu bagi manusia dalam menyimpan, mengolah dan mengorganisasi data. Kecanggihan yang dimiliki oleh sistem informasi akan mempercepat proses pengolahan data sehingga waktu yang dibutuhkan pengguna akan berkurang dibandingkan dengan cara manual [2]. BAK Unila yang memfasilitasi pelayanan PKM mahasiswa seharusnya meyediakan berbagai fasilitas kepada mahasiswa untuk mengikuti program PKM. Kebutuhan mahasiswa terhadap PKM yaitu pelayanan secara administrasi dan pelayanan fasilitas berupa referensi, pelatihan, dan dukungan secara penuh untuk mengikuti PKM. Fasilitas pelayanan PKM hingga saat ini hanya sebatas proses administrasi, pengumuman PKM yang didanai, monitoring internal, dan proses monev (monitoring dan evaluasi). Mahasiswa terlebih mahasiswa yang belum pernah mengikuti PKM sangat membutuhkan referensi dan arahan-arahan untuk mengikuti PKM namun hal tersebut belum difasilitasi sepenuhnya.

Kualitas dan ide proposal PKM sangat berpengaruh terhadap proses penilaian PKM. Peserta PKM seharusnya mengajukan proposal yang benar, unik, dan berkualitas sehingga dapat meningkatkan jumlah proposal yang lolos didanai oleh penyelenggara. Jumlah proposal mahasiswa Universitas Lampung yang didanai hanya mencapai 86 dari 1696 proposal yang diajukan pada tahun 2015 dinilai masih jauh tertinggal dari universitas lain yang jumlah proposal didanai mencapai ratusan setiap tahunnya. Masalah tersebut seharusnya menjadi evaluasi pihak terkait untuk meningkatkan fasilitas serta dukungan untuk meningkatkan kualitas dan kuantitas proposal PKM mahasiswa Universitas Lampung.

Sistem informasi PKM telah banyak dibangun oleh beberapa perguruan tinggi di Indonesia salah satunya yaitu diterapkan pada Biro AK UNS. Perancangan arsitektur enterprise SPPKM pada Biro AK UNS diharapkan sistem yang dibangun bisa konsisten, handal, tidak ada duplikasi data dan redundasi data meskipun terjadi pengembangan sistem yang bisa jadi dilakukan oleh berbagai pihak yang berbeda [3]. Rational Unified Process (RUP) dapat digunakan sebagai metode yang merumuskan model arsitektur enterprise ke dalam aktifitas-aktifitas pengembangan sistem informasi untuk kebutuhan organisasi, dalam hal ini adalah arsitektur sistem informasi perguruan tinggi. Metode RUP lebih mudah dalam menghasilkan desain sistem informasi yang diinginkan organisasi [4]. RUP dapat menjelaskan pengembangan sistem secara real, memiliki dokumentasi sistem yang jelas dan memiliki fleksibilitas dalam proses pengembangan [5]. Sebuah sistem informasi administrasi PKM dibutuhkan untuk menunjang proses bisnis pelayanan PKM di Universitas lampung. Penelitian ini menggunakan metode RUP sebagai metode untuk mengembangkan sistem informasi admistrasi PKM Universitas Lampung.

\section{Metodologi Penelitian}

Rational Unified Process (RUP) adalah proses rekayasa perangkat lunak yang menggunakan pendekatan disiplin untuk menetapkan tugas dan tanggung jawab dalam pengembangan organisasi [6]. RUP baik digunakan karena mendukung 6 (enam) praktik terbaik dalam pengembangan perangkat lunak yaitu pengembangan perangkat lunak secara iteratif, pengelolaan persyaratan, menggunakan arsitektur berbasis komponen, memvisualisasi pemodelan perangkat lunak, secara terus- menerus memverifikasi kualitas perangkat lunak, dan mengawasi perubahan perangkat lunak [7].

Metode yang digunakan pengembangan sistem informasi administrasi PKM adalah Rational Unified Process (RUP). Workflow pada pengembangan sistem informasi administrasi PKM Universitas Lampung ini terdiri dari perencanaan project management, business modeling, requirement, analysis dan design, implementation test, deployment, configuration and change 
management, dan environment workflow. RUP memiliki empat fase tersebut yaitu inception, elaboration, construction, dan transition. RUP dilakukan secara berurutan dan iterative dimana setiap iterasi dapat digunakan untuk memperbaiki iterasi berikutnya.

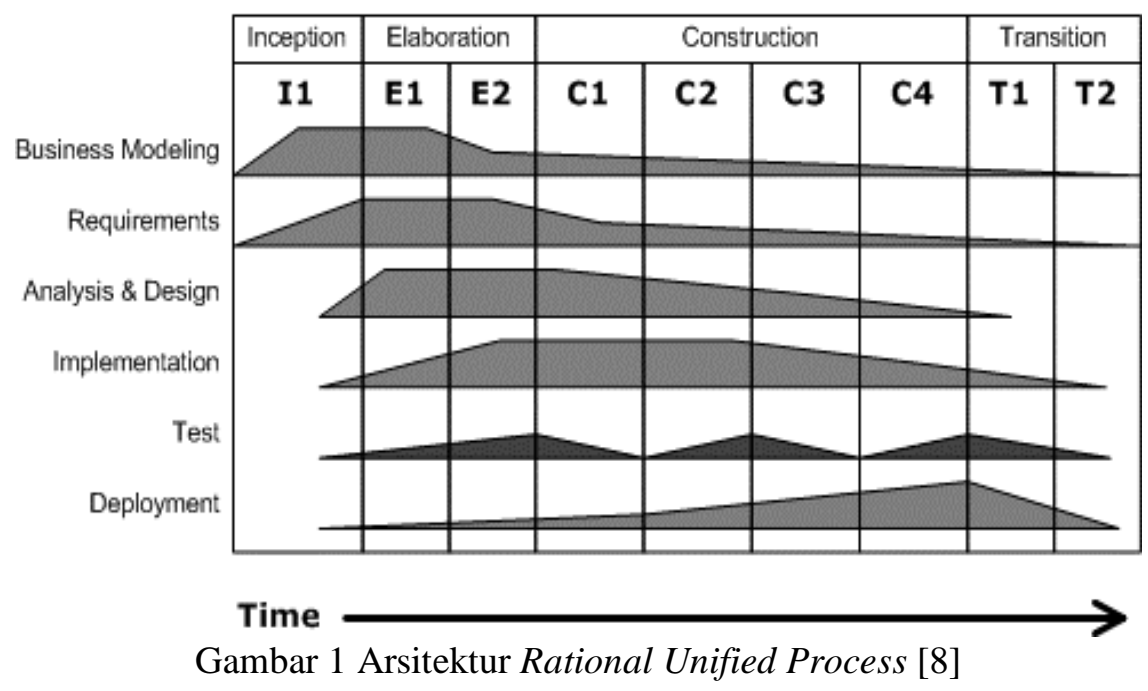

3 Hasil dan Pembahasan

Tahapan yang dalam pengembangan sistem ini ada empat tahap yaitu inception, construction, elaboration, dan transition. Proses yang dilakukan pada tahap inception adalah business modeling dan requirement, kemudian pada tahap elaboration adalah analysis and design dan implementation. Proses yang dilakukan pada tahap construction adalah testing, sedangkan proses pada tahap transition adalah deployment. Proses yang dilakukan pada setiap fase digambarkan pada Tabel 1.

Tabel 4 Proses Pengembangan Sistem Informasi Administrasi PKM Unila

\begin{tabular}{lcccc}
\hline \multirow{2}{*}{ Proses } & \multicolumn{3}{c}{ Fase } \\
\cline { 2 - 5 } & Inception & Elaboration & Construction & Transition \\
\hline Business Modeling & $\mathbf{1}$ & & & \\
\hline Requirement & 2 & & & \\
\cline { 1 - 3 } Analysis \& Design & & 3 & & \\
\cline { 1 - 3 } Implementation & & 4 & 5 & $\mathbf{6}$ \\
\hline Test & & & & \\
\hline Deployment & & & & \\
\hline
\end{tabular}

\subsection{Inception}

Fase inception adalah fase awal yang harus dilakukan dalam penelitian ini, pada fase ini dilakukan beberapa proses yaitu business modeling (menjelaskan visi misi BAK Unila, ruang lingkup proyek, serta business case) dan requirement (menjelaskan kebutuhan sistem yang dibuat). Fase inception lebih fokus terhadap dua proses yaitu business modeling dan requirements.

\subsubsection{Business Modeling}

Business modeling yang dilakukan adalah mendefinisikan visi misi BAK Unila, menjelaskan ruang lingkup proyek dan menggambarkan business use case.

a. Visi BAK Unila 
Terwujudnya layanan terbaik bidang administrasi akademik dan kemahasiswaan menuju tercapainya visi unila

b. Misi BAK Unila

1. Meningkatkan layanan informasi berbasis IT

2. Meningkatkan kecepatan layanan dan akurasi data berbasis IT

3. Meningkatkan kualitas pelayanan yang professional

c. Produk dan Layanan

Biro Akademik dan Kemahasiswaan (BAK) bertugas memberikan layanan administrasi dibidang akademik dan kemahasiswaan di lingkungan Unila. BAK dalam melaksanakan tugas tersebut memiliki fungsi melaksanakan administrasi pendidikan dan administrasi kemahasiswaan. Untuk melaksanakan tugas dan fungsi tersebut BAK terdiri dari dua bagian yaitu Bagian Akademik dan Bagian Kemahasiswaan dimana masing masing bagian terdiri dari beberapa sub bagian. Produk dan layanan bagian akademik meliputi Sistem Informasi Akademik, Registrasi, Wisuda, Evaluasi Dosen, serta Program Akreditasi dan Institusi. Produk dan layanan bagian Kemahasiswaan meliputi administrasi bidang Penalaran, Beasiswa, Asuransi, Prestasi Mahasiswa, dan Alumni. Proses pelayanan PKM ditingkat universitas lampung ditangani oleh bagian Kemahasiswaan.

d. Ruang lingkup proyek

Aktor yang berperan dalam sistem informasi administrasi PKM di Unila ada tiga aktor yaitu user, peserta dan administrator. Proses bisnis pelayanan PKM Unila dengan sistem informasi administrasi PKM ditunjukan pada Gambar 2.

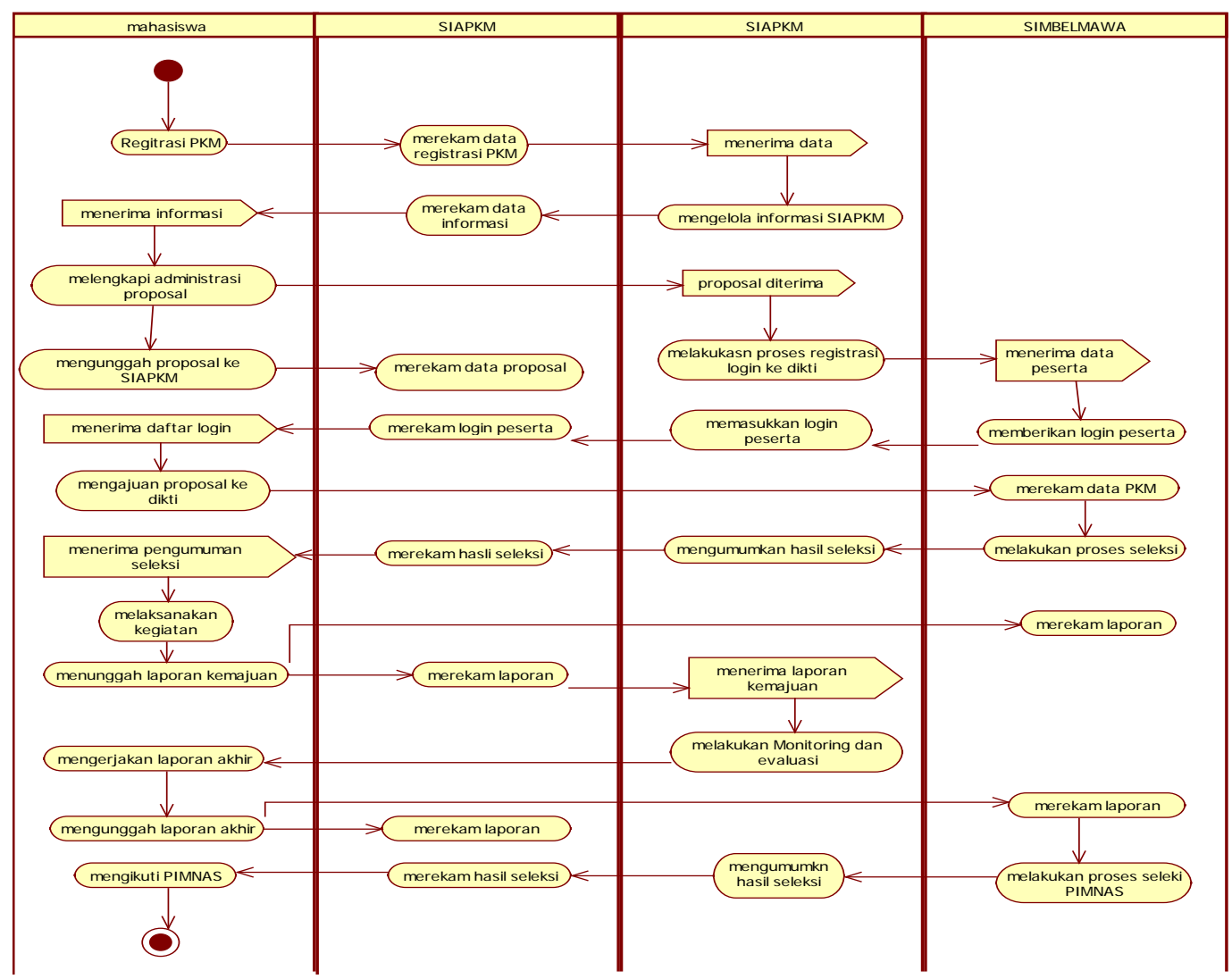

Gambar 2 Proses Bisnis Pelayanan PKM di Universitas Lampung

Administrator dalam hal ini dikelola langsung oleh Tim PKM dari BAK Unila. User adalah pengunjung biasa yang tujuannya hanya melihat data PKM atau berita-berita. Peserta adalah pengguna (mahasiswa) yang melakukan pengisian administrasi data PKM. Administrator adalah orang yang mengatur sistem, baik pengelolaan data PKM atau pengaturan sistem informasi 
administrasi PKM. Proses bisnis menjelaskan secara singkat proses yang dilakukan mahasiswa dari awal sebagai user hingga lulus menjadi PIMNAS.

\subsubsection{Requirements}

Permodelan kebutuhan pada Kebutuhan dari sistem ini adalah melakukan pendataan mahasiswa peseta PKM berkaitan dengan data mahasiswa, dokumentasi PKM, informasi PKM, dan laporan data PKM pada setiap tahunnya. Kebutuhan sistem secara detail digambarkan pada use case diagram. Use Case secara grafis menggambarkan User yang menggunakan sistem dan dengan cara pengguna mengharapkan untuk berinteraksi dengan sistem. Use case diagram pada pengembangan sistem informasi administrasi PKM Unila ini disajikan pada Gambar 3 berikut.

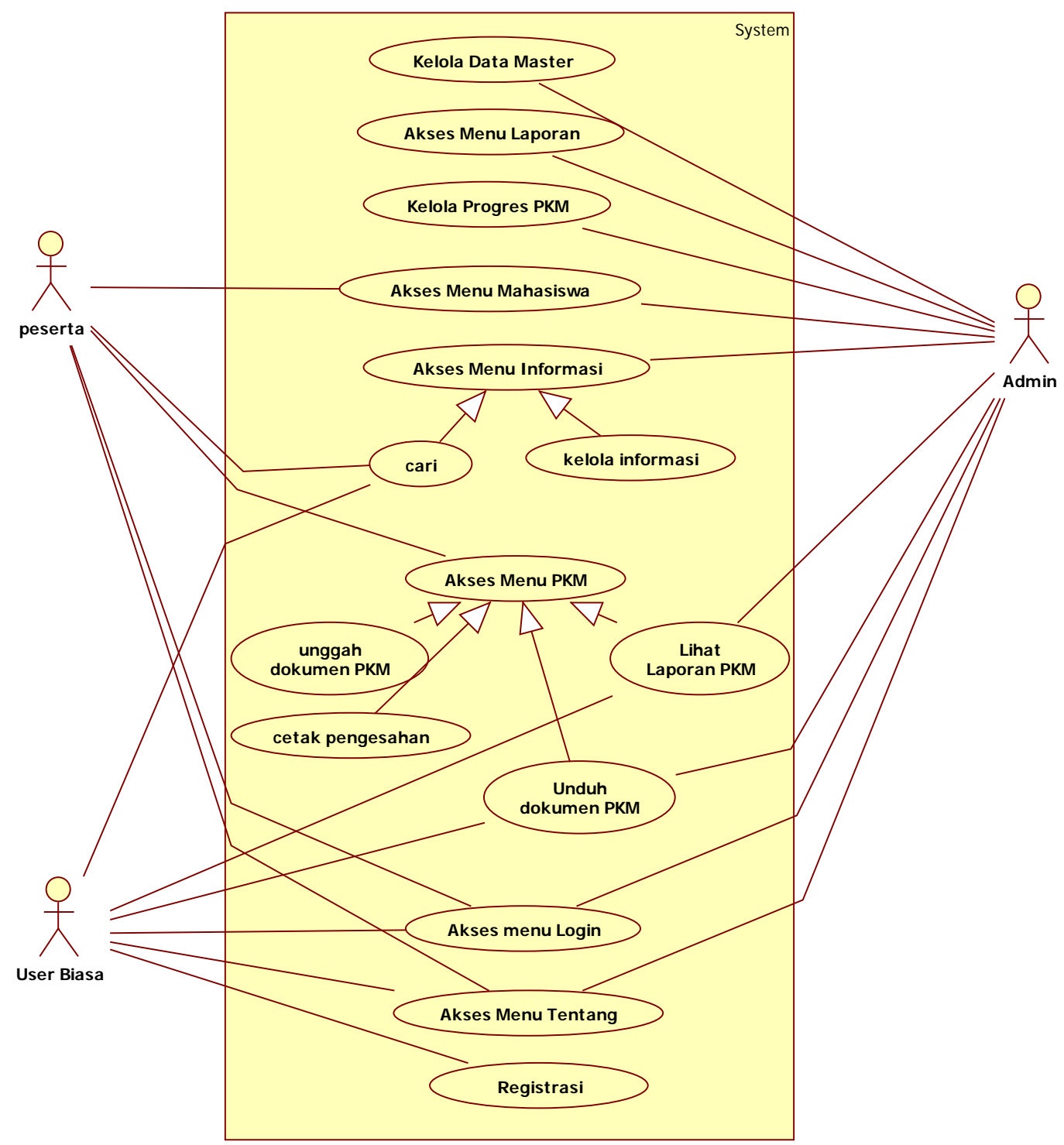

Gambar 3 Use Case Diagram Sistem Informasi Administrasi PKM 


\subsection{Elaboration}

Fase elaboration lebih kepada proses analysis and design dan implementation karena sesuai dengan penjelasan Tabel 1 mengenai arsitektur RUP pada implementasi sistem informasi administrasi PKM, fase elaboration memiliki fokus kerja pada proses analysis design dan implementation.

\subsubsection{Analysis and Design}

Analysis and design yang telah dilakukan pada adalah membuat perancangan sistem menggunakan UML (Unified Modelling Language) dan desain antarmuka. UML sistem informasi administrasi PKM yaitu mencangkup use case diagram, activity diagram, dan sequence diagram masing-masing terdapat 9 diagram.

Rancangan class diagram memiliki tabel yang dibuat pada sistem informasi administrasi PKM berjumlah 15 tabel. Tabel yang diberi nama SIAPKM terdiri dari 8 tabel utama dan 7 tabel pembantu. Tabel utama meliputi tabel mahasiswa, kelompok, pkm, detail pkm, laporan progres, informasi, isi_informasi, dan login. Tabel pembantu antara lain tabel jenis pkm, prodi, jurusan, fakultas, progres, pembimbing, dan periode.

Perancangan antarmuka (interface) merupakan proses penggambaran tampilan suatu sistem dan sebagai acuan pengembang agar memudahkan dalam proses pengembangan sistem. Rancangan antarmuka sistem informasi administrasi PKM memiliki 10 halaman pokok, yaitu Kelola Data Master, Laporan, Progress PKM, Mahasiswa, Informasi, PKM, Login, Tentang, Registrasi, serta Beranda.

\subsubsection{Implementation}

Implementasi yang dilakukan adalah implentasi database dan implementasi sistem. Implementasi database adalah mengimplementasikan entity relationship diagram ke dalam bentuk database. Prosedur pertama dalam membuat database sistem informasi administrasi PKM adalah dengan membuat 8 tabel utama yaitu tabel mahasiswa, tabel pkm, tabel kelompok, tabel detail_kelompok, tabel laporan_progres, tabel informasi, tabel isi_informasi, dan tabel login. Class diagram pada sistem informasi administrasi PKM disajikan pada Gambar 4. 


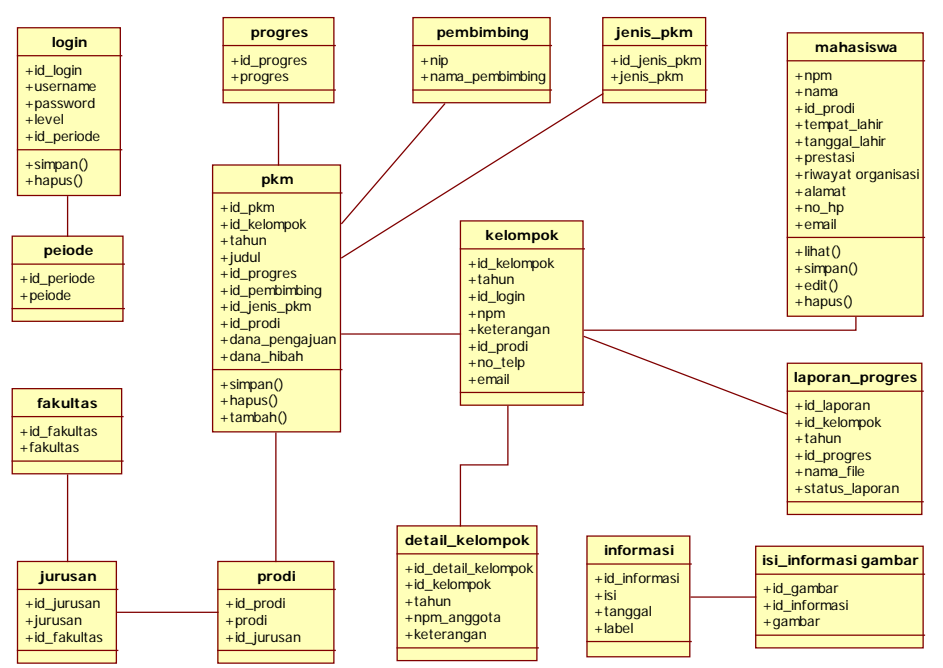

Gambar 4 Class Diagram Sistem Infornasi Administrasi PKM

Proses pada implementasi sistem yaitu menjelaskan setiap halaman sistem. Sistem informasi adminitrasi PKM memiliki 19 halaman utama dan halaman pendukung. Pembuatan halaman pada sistem berdasarkan kebutuhan yang telah termuat dalam use case diagram. Implementasi halaman beranda pada sistem informasi administrasi PKM disajikan pada Gambar 4.

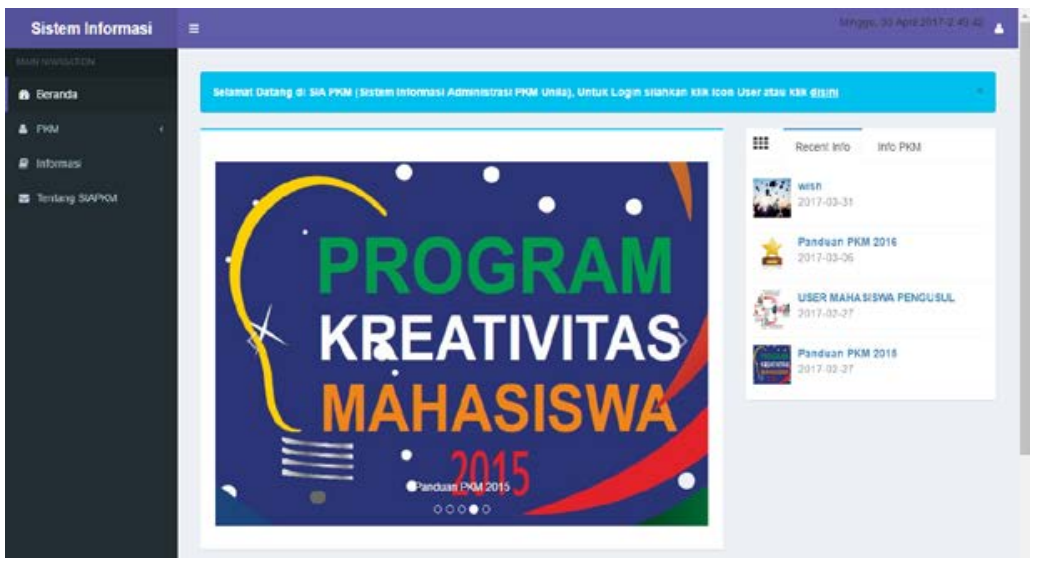

Gambar 5 Implementasi Halaman Beranda Sistem Informasi Administrasi PKM

\subsection{Construction}

Tahap construction pada pengembangan sistem sistem informasi administrasi PKM yaitu proses testing. Proses testing dilakukan terhadap hasil implementasi database dan implementasi sistem pada tahap elaboration. Hasil testing (pengujian) sistem informasi administrasi PKM menggunakan pengujian black box testing yaitu equivalence partitioning. Black box testing adalah pengujian yang memfokuskan pada kebutuhan fungsional perangkat lunak dengan tujuan berusaha menemukan kesalahan [9]. Pengujian dilakukan oleh lima orang mahasiswa sebagai tahap pengujian awal. Rekapitulasi hasil pengujian seperti disajikan pada Tabel 2.

Tabel 5 Rekapitulasi Hasil Pengujian Equivalence Partitioming

\begin{tabular}{cccc}
\hline $\begin{array}{c}\text { Jumlah } \\
\text { Pengujian }\end{array}$ & Validitas & Jumlah Validitas & $\begin{array}{c}\text { Tingkat Keberhasilan } \\
\text { Sistem }\end{array}$ \\
\hline \multirow{2}{*}{198} & Valid & 181 & $91,41 \%$ \\
\cline { 2 - 4 } & Tidak Valid & 17 & $8,59 \%$ \\
\hline
\end{tabular}


Pengujian ini dilakukan oleh 1 orang perwakilan Tim PKM dan lima orang perwakilan mahasiwa Universitas Lampung. Pengujian produk perangkat lunak dilakukan dengan menggunakan Alpha Testing. Alpha Testing adalah pengujian yang dilakukan oleh pemakai pada lingkungan pengembang, dalam hal ini lingkungan yang terkendali [10]. Pengujian juga dilakukan dengan memberikan beberapa uji kasus yang berfokus pada fungsional sistem. Pengujian ini bertujuan untuk mengetahui apakah sistem sudah dapat digunakan dengan baik dan dapat membantu kinerja TIM pengelola PKM Universitas Lampung. Hasil pengujian dapat dilihat pada tabel bahwa tingkat keberhasilan mencapai 91,41 \% sehingga dapat disimpulkan bahwa fungsi-fungsi pada sistem berjalan dengan baik dan menunjukkan sistem sudah dapat digunakan

Bagian sistem informasi administrasi PKM yang perlu di perbaiki antara lain pada halaman unggah laporan sebaiknya hanya dapat mengunggah laporan dalam bentuk $p d f$. Halaman laporan pada laman administrator terdapat fungsi-fungsi yang perlu diperbaiki yaitu logika pada form pemilihan tahun (seharusnya tahun awal<tahun akhir), pada field fakultas dan jurusan seharusnya data wajib diinputkan atau terdapat peringatan jika tidak diinputkan. Halaman mahasiswa pada laman administrator terdapat beberapa fungsi yang harus diperbaiki yaitu fungsi edit dan hapus mahasiswa. Menu Bar pada lama peserta dan administrator terdapat fungsi yang tidak dapat berjalan yaitu menu profil yang seharusnya berisikan data pengguna. Dokumentasi pengujian dapat dilihat pada lampiran.

\subsection{Transition}

Fase ini adalah fase terakhir yang ada pada metode rational unified process. Fase ini memfokuskan pada proses deployment system (instalasi sistem). Proses deployment yang dilakukan adalah melakukan instalasi sistem, sosialisasi penggunaan sistem serta mendapatkan feedback. Pihak BAK Unila segera membuat sebuah kebijakan untuk memaksimalkan penggunaan sistem yaitu menetapkan alur PKM pada sistem sistem informasi administrasi PKM dalam proses pelaksanaan PKM. Sistem akan dipasang pada server di lingkungan Universitas Lampung jika sudah diperbaiki dan diuji kembali. Uji Coba instalasi sistem versi Alpha sudah dilakukan pada bulan Juni 2017 dan bisa diakses di www.siapkm-unila.xyz.

\section{Kesimpulan}

Simpulan dari penelitian yang telah dilakukan sebagai berikut.

1. Sistem informasi administrasi PKM Universitas Lampung berhasil dibangun menggunakan metode Rational Unified Process (RUP) dengan pengujian equivalence partitioning dan versi pengujian alpha dengan tingkat keberhasilan 91,41\%.

2. Fungsi-fungsi yang terdapat pada sistem informasi administrasi PKM dapat berjalan dengan baik dan dapat digunakan untuk melayani proses pendaftaran, mengunggah dokumen laporan kemajuan, dan melihat pengumuman terkait PKM.

3. Sistem menyediakan halaman edit progres peserta PKM untuk administrator menyeleksi peserta PKM yang lolos ke tahap selanjutnya. Sistem informasi administrasi PKM juga dapat digunakan untuk menyimpan arsip data mahasiswa peserta PKM dan dokumen PKM mahasiswa Universitas Lampung pada database yang terdapat pada sistem. Sistem informasi administrasi PKM juga menyediakan fitur cetak halaman pengesahan untuk mengurangi kesalahan administrasi dalam proses melengkapi berkas pendaftaran PKM dan fitur laporan data PKM

\section{Saran}

Saran untuk penelitian selanjutnya sebagai berikut. 
1. Sistem menyediakan fitur notifikasi pada sistem web untuk menandakan aktifitas terbaru yang belum dilihat oleh pengguna.

2. Sistem menyediakan fitur chatroom agar memudahkan komunikasi user atau peserta dengan tim PKM Universitas.

3. Sistem menyediakan fitur upload informasi dengan format video (MP4, Avi,flv, dsb.).

4. Halaman edit progres pada sistem perlu diperbaiki dengan menambahkan fitur select untuk mengubah status progres kelompok PKM agar memudahkan administrator dalam mengolah data progres. Halaman edit progress juga perlu ditambahkan fitur untuk mengubah progres kembali untuk kelompok yang telah diubah progres kelompoknya untuk menghindari apabila terjadi kesalahan pada pengubahan data.

$6 \quad$ Referensi

[1] Pedoman Program Kreativitas Mahasiswa ( PKM ) 2015. Direktorat Riset Dan Pengabdian Masyarakat, Direktorat Jenderal Penguatan Riset dan Pengembangan, Kementerian Riset, Teknologi Dan Pendidikan Tinggi. Jakarta.

[2] Widyarti, I., S. Andayani., K. Hernawati. 2012. Sistem Informasi Kegiatan Dosen dalam Tridharma Perguruan Tinggi. Matematika-S1. 3(3). M1-M9.

[3] Rini A. dkk. 2013. Arsitektur Bisnis Biro Administrasi Kemahasiswaan (AK) Pada Perancangan Arsitektur Enterprise Universitas Sebelas Maret Menggunakan Framework TOGAF. SEMANTIK 2013 ISBN: 979-26-0266-6

[4] Yunis, R., Suhendro. K. 2009. Model Enterprise Architecture untuk Perguruan Tinggi di Indonesia. Semnas IF 2009 ISSN: 1979-2328. (UII, Yogyakarta), E72-E79

[5] Syam, Ahmad Khoiruddin. 2015. Pengembangan Sistem Tracer Study Jurusan Ilmu Komputer Menggunakan Metode Rational Unified Process (RUP). Skripi. Universitas Lampung.

[6] Manalil, J. 2010. Rational Unified Process. Cochin University of Science and Technology. India.

[7] Fajriyah, H. 2011. Rancang Bangun Aplikasi Hasil Terapi Anak Autis Menggunakan Metode Logika Fuzzy (Studi Kasus Badan Pendidikan dan Pelatihan Sekolah Khusus Thandur Childhood Centre). UIN Syarif Hidayatullah. Jakarta.

[8] Rational Software. 1998. Rational Unified Process Best Practices for Software Development Teams. Rational Software. California

[9] Gries, David, Fred B. Schneider. 2005. An Integrated Approach to Software Engineering Third Edition. Pankaj Jalote. Indian Institute of Technology Kampur India.

[10] Wibisono, W., Baskoro, F.2002. Pengujian Perangkat Lunak dengan Menggunakan Model Behaviour UML. JUTI:(ITS, Surabaya), Volume 1 No 1 43-50. 